\title{
The Effectiveness of Postpartum IUD Compared to Interval IUD in 'Aisyiyah Hospital Klaten
}

\author{
Ivanna Beru Brahmana ${ }^{1 *}$ (D), Ana Majdawati ${ }^{2}$, Inayati Inayati ${ }^{3}$ (D) \\ ${ }^{1}$ Department of Obstetrics and Gynecology, Medical Study Program, Faculty of Medicine and Health Sciences, Universitas \\ Muhammadiyah Yogyakarta, Indonesia; ${ }^{2}$ Departement of Radiology, Medical Study Program, Faculty of Medicine and Health \\ Sciences, Universitas Muhammadiyah Yogyakarta, Indonesia; ${ }^{3}$ Departement of Medical Microbiology, Medical Study Program, \\ Faculty of Medicine and Health Sciences, Universitas Muhammadiyah Yogyakarta, Indonesia
}

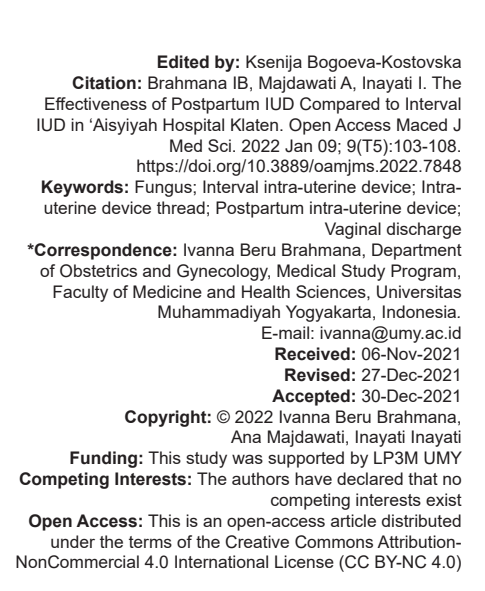

\section{Introduction}

During this pandemic, long-term family planning methods are preferred because the schedule for visiting health facilities is not as frequent as short-term family planning methods. In this case, Intra-uterine device (IUD) is one of the long-term contraceptive methods besides implants. Intrauterine devices and implants, as longterm contraceptive methods, show lower pregnancy rates than short-term methods [1]. The advantages of IUD insertion and postpartum implants are that they have both high efficacy and reversibility, also easy to insert by trained health personnel [2]. Postpartum IUD (PPIUD) insertion is performed ten minutes after the placenta is born until 48 hours postpartum, while the interval insertion method is not associated with delivery. What is meant by the interval period is the insertion of the IUD after four weeks after delivery. Insertion of the IUD after 4 weeks postpartum, or usually 6 weeks postpartum, is considered a traditional IUD insertion. In India, postpartum IUD insertion is gaining popularity [3].
The use of contraception will provide a distance between pregnancies not to be too close. The use of PPIUD and postpartum implants prevents accidental pregnancies and too close pregnancy [4]. A pregnancy that is too close is risky for both mother and baby. The risk to the mother causes her not to have time for herself, especially if the mother has a congenital disease so that she does not have time to complete her recovery. In addition, the too close pregnancy of mothers who give birth with a history of cesarean section will be at risk of uterine rupture [5]. The use of postpartum implants has a lower risk of weight gain than the use of injectable contraceptives [2]. Thus, the risk of obesity is lower, so it is hoped that mothers will be healthier and avoid unwanted pregnancies. Meanwhile, the risks for the baby are slow fetal growth, preterm labor, and increased morbidity and mortality for babies. Short pregnancy intervals in adolescents (aged 10-18 years) increase the risk of preterm birth, lower birth weight, and stillbirth [6]. The use of postpartum implants does not interfere the breastfeeding mothers [2]. Thus, the baby gets enough milk intake needed for the baby's health. 
Specifically, as a developing country, Indonesia has a high maternal mortality rate. ASEAN Maternal Mortality Rate 2015 showed that Laos is the highest with MMR 220 death/1000 live births, then Myanmar 212 death/1000 live births and Indonesia is 190 death/1000 live births. The lowest MMR is Singapore with 2.4 death/1000 live births [7].

The risk of this maternal mortality can be reduced by the high use of contraception in the community. The use of contraception, in addition to preventing unwanted pregnancies, is also an effort to achieve the $5^{\text {th }}$ goal of the Millennium Development Goals, namely improving maternal health [5]. Regarding this, IUDs are still the preferred choice of long-term contraceptive method in Indonesia. In 2015, the coverage of IUD contraception in Indonesia was 7.3\%, and implants were $6.21 \%$ [8]. The impact of the pandemic on the family planning program was a decrease in family planning services at health service facilities, this was related to the disruption of the supply chain of contraceptive devices and drugs due to the disruption of the mobility of officers in the field. Communication, Educational Information (CIE) Reproductive Health, Family Planning activities have also decreased because group-based activities in the community have limited mobility due to the application of physical and social distancing, it is highly recommended for maternity mothers to perform PPIUD insertion during parturition. Postpartum IUD insertion is recommended when providing education to pregnant women because it has the advantage of being reversible over sterilization [2]. However, the family planning outreach in Indonesia is not as intense as the slogan of two children is enough. The use of contraception in Indonesia in the last decade has not increased, instead there has been an increase in unmet need [9]. This condition still occurs even though the provision of information, education, and communication is always carried out [10]. Currently, the slogan of the National Family Planning Coordinating Board as a family planning institution in Indonesia is Bangga Kencana. This slogan accentuates that a prosperous family is a planned family. The success of family planning is in line with the decrease in unmet need. The main causes of unmet need include lack of knowledge about the pregnancy risks, fears of side effects and health problems, prohibition on the use of contraceptives, for example, husbands do not allow it, cost problems, subjective assumption that pregnancy does not occur even without contraception [11].

Therefore, the use of contraception is then introduced when pregnant women perform ANC, hoping that they will immediately choose family planning after giving birth. Thus, when the mother is discharged from the hospital, it is safe for her pregnancy to be thinned out for at least in the next 2 years.

Moreover, the problem often asked by prospective acceptors when the postpartum IUD is introduced is whether the IUD does not come off easily because of the large size of the uterus. Therefore, this paper presents how the complaints and complications are likely to be encountered with postpartum IUD compared to interval IUD. If the postpartum IUD's effectiveness and efficiency are better, it will increase family planning coverage and reduce maternal mortality. In line with research conducted in India, PPIUD insertion increases family planning coverage rates [3]. PPIUD insertion reduces the incidence of unwanted pregnancies [5], thus, it is expected to reduce the risk of maternal death.

In previous research, several things have been explained about this question. One of them explicated that the expulsion incidence was $12 \%$ for the PPIUD insertion after vaginal delivery, $0 \%$ for PPIUD insertion during sectio caesarea, and $6 \%$ at interval IUD. However, the perforation incidence was not found in all study groups [3]. Katheit stated that knowledge about PPIUD was much lower than interval IUD insertion $(5.79 \%$ vs. $73.55 \%$ ). Therefore, the acceptance of PPIUD insertion at the age between 21 and 25 years was $50.88 \%$. Then, the expulsion incidence was $10.5 \%$, but there was no perforation incidence or other major complications. Concerning this, the PPIUD insertion is said to be safe, has high effectiveness, has long-term effects, and is a low-cost contraceptive. Moreover, the expulsion incidence can be reduced if the family planning officers are more trained and the PPIUD insertion is inserted into the uterine fundus [12]. Post-partum IUD insertion did not increase the incidence of bleeding, pain, and the risk of infection. In addition, there was also no incidence of uterine perforation. These conditions support the safety and effectiveness of PPIUD insertion [3]. In the absence of an increased risk of infection, bleeding, pain, and uterine perforation, it is safe to install a PPIUD [2]. Insertion of the Cu375 IUD is recommended during cesarean delivery to prevent the occurrence of unmet needs because it is proven to be safe, effective, and comfortable [13].

A study was conducted for 2 years, from January 2016 to December 2017, by Makins et al., by carrying out PPIUD insertion counseling involving 6477 trained health providers; a total of 219,242 people were counseled out of 239,033 childbirth that took place. It could be concluded that the family planning acceptance, especially PPIUD insertion in several different countries, revealed different responses according to local culture, and it is impossible to generalize it to all countries [14].

Another research affirmed that PPIUD insertion ten minutes after placenta detachment is a potential contraceptive to reduce the incidence of unwanted pregnancies and the short distance between pregnancies [15]. The purpose of the study is to know the effectiveness of PPIUD and the interval IUD based on acceptors complaints and complications. 


\section{Methods}

This research method was cross-sectional analytic, the relationship between the types of IUD insertion, namely PPIUD and IUD intervals with complaints from the husband, the results of the inspeculo inspection (presence or absence of erosion and expulsed IUD or not), the presence or absence of fungi, bacteria, menstrual complaints, pain, ultrasound examination results. The research subjects consisted of women with vaginal and sectio caesarea (SC) deliveries in the maternity room and operating room at RSIA 'Aisyiyah Klaten, with PPIUD installed that conformed to the inclusion and exclusion criteria. Meanwhile, interval IUD in this study was the respondents who inserted the IUD, and it was not related to the time of delivery. Inclusion criteria encompassed women with vaginal and sectio caesarea (SC) deliveries with normal temperature $\left(<37^{\circ} \mathrm{C}\right)$, intact or ruptured amniotic before $18 \mathrm{~h}$, no untreated postpartum hemorrhage, and were willing to sign an informed consent for the research. Exclusion criteria comprised mothers giving birth with comorbidities, such as asthma, heart disease, diabetes mellitus, hypertension, anemia, and allergies. Besides, this research has received ethical approval from the Health Research Ethics Commission, Universitas Muhammadiyah Yogyakarta, with number 181/ EC-KEPK FKIK UMY/X/2020.

\section{Results}

Table 1 shows the research subjects' characteristics. The study's total sample was 129 participants consisting of $82(63.6 \%)$ PPIUD and $47(36.4 \%)$ IUD intervals. In total, of the 129 IUD participants based on the educational level, the most were Senior High School with 53 (41.1\%), followed by Bachelor with 43 (33.3\%) participants, diploma with $18(14.0 \%)$, and other education (Elementary School, Junior High School, Master Program/Doctoral Program) with a mean of 2-7 participants (1.6-5.4\%). Besides, most IUD participants did not work, as many as $66(51.2 \%)$, while private employees were $20(15.5 \%)$. In this research, IUD participants revealed that 104 were multigravidas (80.6\%), and 25 (19.4\%) were primigravida. Then, participants who controlled/checked the IUD in health services were 93 (72.1\%), while $35(27.1 \%)$ participants had never had an IUD control. In addition, the participants who complained of vaginal discharge were quite a lot, as many as 85 (65.9\%), while $44(34.1 \%)$ participants did not complain. Furthermore, there were complaints of irregular menstruation as many as $22(17.1 \%)$ participants, while regular menstruation was $107(82.9 \%)$.
Table 1 regarding IUD complaints, most participants did not complain of pain, as many as $80(62.0 \%)$ participants, while $49(38.0 \%)$ participants complained of pain. Meanwhile, during sexual intercourse, on average, $126(97.7 \%)$ participants did not experience complaints and felt fine, and only three (2.3\%) participants experienced complaints.

Table 1: Characteristics of research subjects

\begin{tabular}{|c|c|c|c|c|c|}
\hline \multirow[t]{2}{*}{ Characteristics } & \multirow[t]{2}{*}{ Classification } & \multicolumn{2}{|c|}{ IUD Interval } & \multicolumn{2}{|c|}{ PPIUD } \\
\hline & & Freq & $(\%)$ & Freq & $(\%)$ \\
\hline \multirow[t]{4}{*}{ Last education } & Senior high school & 22 & 46.8 & 32 & 39.0 \\
\hline & Bachelor & 20 & 42.5 & 28 & 34.2 \\
\hline & Diploma & 2 & 4.3 & 16 & 19.5 \\
\hline & Other & 3 & 6.4 & 6 & 7.3 \\
\hline \multirow[t]{4}{*}{ Mother's job } & Housewife & 21 & 44.7 & 47 & 57.3 \\
\hline & Civil servants & 10 & 21.3 & 14 & 17.1 \\
\hline & Private & 9 & 19.1 & 9 & 11.0 \\
\hline & Entrepreneur & 7 & 14.9 & 12 & 14.6 \\
\hline \multirow[t]{3}{*}{ Parity } & Primigravida & 5 & 10.7 & 19 & 23.2 \\
\hline & Secundigravida & 22 & 46.8 & 39 & 47.5 \\
\hline & Multigravida & 20 & 42.5 & 24 & 29.3 \\
\hline \multirow[t]{2}{*}{ IUD control } & Ever control & 28 & 59.6 & 65 & 79.3 \\
\hline & Never control & 19 & 40.4 & 17 & 20.7 \\
\hline \multirow[t]{2}{*}{ Vaginal discharge } & Yes & 26 & 55.3 & 59 & 71.9 \\
\hline & No & 21 & 44.7 & 23 & 28.1 \\
\hline \multirow[t]{2}{*}{ Regular menstruation } & Yes & 35 & 74.5 & 73 & 89.0 \\
\hline & No & 12 & 25.5 & 9 & 11.0 \\
\hline \multirow[t]{2}{*}{ Pain } & Yes & 13 & 27.7 & 34 & 41.5 \\
\hline & No & 34 & 72.3 & 48 & 58.5 \\
\hline \multirow[t]{2}{*}{ Husband's complaints } & Yes & 3 & 6.4 & 0 & 0 \\
\hline & No & 44 & 93.6 & 82 & 100.0 \\
\hline \multirow[t]{2}{*}{ Ultrasound results abnormalities } & Yes & 1 & 2.2 & 2 & 2.4 \\
\hline & No & 46 & 97.8 & 80 & 97.6 \\
\hline \multirow[t]{2}{*}{ Results of inspeculo: erosion } & Yes & 19 & 40.4 & 19 & 25.6 \\
\hline & No & 28 & 59.6 & 61 & 74.4 \\
\hline \multirow[t]{6}{*}{ Level of erosion abnormalities } & Light & 14 & 29.8 & 13 & 15.9 \\
\hline & Moderate & 4 & 8.5 & 4 & 4.9 \\
\hline & Heavy & 1 & 2.2 & 2 & 2.4 \\
\hline & No Abnormalities & 28 & 59.6 & 61 & 74.4 \\
\hline & IUD failed & 0 & 0.0 & 1 & 1.2 \\
\hline & No data & 0 & 0.0 & 1 & 1.2 \\
\hline \multirow[t]{4}{*}{ Inspeculo with thread } & Yes & 35 & 74.5 & 34 & 41.5 \\
\hline & No & 12 & 25.5 & 45 & 54.9 \\
\hline & IUD failed & 0 & 0.0 & 1 & 1.2 \\
\hline & No data & 0 & 0.0 & 2 & 2.4 \\
\hline
\end{tabular}

IUD: Intra uterine device, PPIUD: Post partum intra uterine device, freq: Frequency.

In addition, the gynecological ultrasound examination results showed that $126(97.7 \%)$ participants had no abnormalities, while three $(2.4 \%)$ showed abnormalities. The Inspeculo results revealed that $89(69.0 \%)$ examinations found no erotion/redness of the uterine cervix, and $40(31.0 \%)$ participants did not find abnormalities. On inspeculo examination based on the abnormality level, the highest was mild level with $58(45.0 \%)$ participants, followed by moderate level with $48(37.2 \%)$ participants and heavy level with $10(78 \%)$ participants, and no vaginal discharge in $13(10.1 \%)$ participants. On inspection of the presence or absence of threads, 68 people saw the IUD thread, while 61 people $(47.3 \%)$ did not see the thread.

Table 2 displays the research subjects' microscopic examination results. In the vaginal swab microbiological culture results, the most pathogenic bacteria were found in 119 (92.2\%) participants, while ten $(7.8 \%)$ participants were normal. It was found positive in 75 (58.1\%) participants for fungus swab results, while no fungus was found in 54 (41.9\%) participants. In addition, Gram-negative diplococcus bacteria were found in $18(14.0 \%)$ participants, while $111(86.0 \%)$ participants had negative results. 
Table 2: The research subject's microscopic examination results

\begin{tabular}{llll}
\hline Characteristics & Classification & Frequency & $(\%)$ \\
\hline Bacterial vaginal swab examination & Yes & 119 & 92.2 \\
& No & 10 & 7.8 \\
Fungus & Yes & 75 & 58.1 \\
& No & 54 & 41.9 \\
NGO* & Yes & 18 & 14.0 \\
& No & 111 & 86.0 \\
Total & & 129 & 100 \\
\hline${ }^{*}$ NGO: Neisseseria gonorrhea & &
\end{tabular}

Table 3 exhibits the bivariate analysis results of the research subjects. Four variables showed significant results with a $p<0.05$. The significant variables consisted of husband's complaint $(p=0.021)$, erosion ( $p=0.011)$, inspeculo with a thread $(p=0.01)$, and the presence of fungi $(p=0.000)$. Meanwhile, seven other variables, including menstruation complaints, vaginal discharge complaints, pain, ultrasound results, inspecules that described the vaginal discharge level, presence or absence of bacteria, presence or absence of NGO, exposed insignificant results, with $p>0.05$.

Table 3: Bivariate analysis results

\begin{tabular}{ll}
\hline Variable & $\mathrm{p}$-value of the IUD Effectiveness \\
\hline Husband's complaints & 0.021 \\
Erosion & 0.011 \\
Inspeculo with thread & 0.01 \\
Fungus & 0.000 \\
Menstrual complaints & 0.53 \\
Vaginal discharge complaints & 0.55 \\
Pain & 0.146 \\
Ultrasound results & 0.69 \\
Inspeculo of vaginal discharge level & 0.304 \\
Bacteria & 0.660 \\
NGO & 0.708 \\
\hline${ }^{*}$ Significant if $P<0.05$. &
\end{tabular}

\section{Discussion}

Besides, the vaginal bleeding incidence in PPIUD was around $7 \%$, the expulsion incidence was $5 \%$, while the shifted IUD incidence was $2 \%$, but there was no perforation incidence [16]. The perforation incidence was also not found in the PPIUD insertion. The total expulsion incidence was found in six cases $(7.5 \%)$, whereas those with partial expulsion were found in eight cases (10\%). In this regard, the PPIUD insertion was an easy thing to do, stated by $93 \%(n=74)$ of operators [17]. Post-SC PPIUD insertion showed that the expulsion incidence at 6 weeks after insertion was $6.1 \%(7 / 114)$, expulsion in the year of insertion was $8.8 \%$, no perforation incidence, and one infection incidence. In addition, the continued use of the IUD in a year reached $84.8 \%$. Therefore, as many as $92.7 \%$ of respondents felt they were compatible with the IUD they had worn within a year of use [18].

In the evaluation six months after PPIUD insertion, the infection incidence was $0.8 \%$, there was no perforation incidence in $98.3 \%$ of respondents, thus recommending the use of IUDPP and the total expulsion incidence was $29.8 \%(n=113)$ [19]. Besides, the IUD malposition incidence was $10.4 \%$, identified by ultrasound examination. Most malposition sites (73.1\%) were in the lower uterine or cervical segment [20]. Further, the continued use rate at 6 months was $81.81 \%$ for the interval IUD and $88.23 \%$ for the IUDPP. The complication incidence was $15.33 \%$ for the PPIUD and $19.33 \%$ for the interval IUD. Meanwhile, the expulsion rate incidence in the PPIUD was $6.96 \%$ and $2.2 \%$ in the IUD interval, with $p<0.05$ [21].

Furthermore, the incidence of no visible thread was $29 \%$, the expulsion incidence was less in post-SC respondents (aOR 0.33; 95\% Cl, 0.26-0.41), whereas in those inserted vaginally, aOR $0.59 ; 95 \% \mathrm{Cl}, 0.42-$ 0.83 [22]. Besides, the PPIUD insertion by midwives had several complications in the form of infection in the uterus by $2.7 \%$, the expulsion incidence was $2.3 \%$, and IUD removal was $4.4 \%$ [23]. Meanwhile, serious complications were not found with post-SC PPIUD; the incidence of expulsion rates, PPIUD release due to bleeding or pain, and other medical reasons, respectively, were $17.6,8.2$, and $2.4 / 100$ women per year. In addition, the rates of continued use of the IUD at six months and 12 months were $81.6 \%$ and $62 \%$ [24].

The highest incidence of expulsion was found in vaginal PPIUD (12\%), compared to post-SC PPIUD (0\%), and at the IUD interval of $6 \%$, it was statistically significant $(=0.037)$. The incidence of other complications in the form of heavy bleeding, pain, infection in the PPIUD was almost the same as the interval IUD and was not statistically significant $(p=0.972)$. The perforation incidence was not observed in either group [3]. On the other hand, the apparent incidence of IUD thread was in different types of IUD of Cu375 and CuT380A at six weeks post-SC insertion evaluation, $97.9 \%$, and $41.7 \%$, respectively. The incidence at three months was $100 \%$ in the Cu375 group and $47.9 \%$ in the CuT380A ( $p<0.001)$ [13].

In this case, the threads would appear in the PPIUD at week six and three months less than the interval IUD. Then, in the PPIUD, the risk of expulsion was zero, whereas, in the IUD interval, it was 5/84 (5.95\%) [25]. Expulsion was higher for levonorgestrel intrauterine system users $(21 / 55$ or $38 \%)$ than for copper intrauterine device users (8/41 or $20 \%$ ) (odds ratio, 2.55; 95\% confidence interval, 0.99e6.55; P $1 / 40.05$ ) [26]. The risk of expulsion in immediate and early postpartum placements was higher than interval placement (adjusted RR 7.63, 95\% Cl 4.31-13.51; adjusted RR 6.17, 95\% Cl 3.19-11.93, respectively). Risk of expulsion in postpartum placement less than 4 weeks after vaginal delivery was higher than cesarean delivery (adjusted RR 5.19, 95\% Cl 3.85-6.99). Risk of expulsion at less than 4 weeks postpartum that the levonorgestrel intrauterine system was higher than CuT380A [27].

The existence of the IUD as one of the causes of vaginal discharge [28] was proven in this study, where vaginal discharge was found in both IUDPP acceptors and IUD intervals. Neisseria gonorrhea was 
found in $14 \%(18 / 129)$ in this study, which may progress to cervicitis. Hay said that cervicitis is associated with gonorrhea, chlamydia, or Mycoplasma genitalium, which will appear as vaginal discharge [28]. Gonorrhea is one of the five reproductive tract infectious diseases [29].

In the vaginal discharge, blood clots can be found, causing complaints of bleeding outside the menstrual cycle or irregular menstruation. Complaints of post-coital bleeding or bleeding after a vaginal swab are often found [28]. This indicates an erosion/wound on the portion or cervix so that when rubbed on a vaginal swab examination, it will bleed.

In this study, the incidence of erosion in the IUD interval was higher than the IUDPP $40.4 \%$ (19/47) versus $25.6(19 / 80)$. In line with the higher incidence of regular menstruation in IUDPP $89 \%(73 / 82)$ than IUD interval $74.5 \%$ (35/47), where due to cervicitis it is possible to have bleeding outside the menstrual cycle as described above. Thus, the possibility of more NGOs being found at interval IUDs cannot be ruled out.

The weakness of this study is that it cannot be explained why vaginal discharge in IUDPP is lower than IUD interval. Further research is needed with a larger number of samples.

The incidence of pain in the IUDPP was $41.5 \%$ (34/82) higher than the IUD interval of $27.7 \%$ (13/47), possibly because the rhythmic contractions of the uterus that had just given birth in the process of involution could not be ruled out. The husband did not complain about the IUDPP compared to the interval IUD, which was $0 \%$ versus $6.4 \%(3 / 47)$, possibly because the IUDPP installation counseling involved the presence of the husband who was waiting for his wife who was about to give birth. Thus, the husband's acceptance of the IUD thread is better than the interval IUD, where the husband is not necessarily present at the time of insertion.

\section{Conclusion}

There was a significant relationship between the type of IUD insertion and the husband's complaints $(p=0.021)$, the erosion incidence $(p=0.011)$, the presence or absence of threads during inspeculo examination $(p=0.01)$, and the presence of fungi $(p=0.00)$. PPIUD is more effective than interval IUD.

\section{Acknowledgments}

The authors thank LP3M UMY for funding this research. There was no conflict of interest in this research.

\section{References}

1. Tocce KM, Sheeder JL, Teal SB. Rapid repeat pregnancy in adolescents: Do immediate postpartum contraceptive implants make a difference? Am J Obstet Gynecol. 2012;206(6):481. e1-7. https://doi.org/10.1016/j.ajog.2012.04.015 PMid:22631865

2. Mwalwanda CS, Black KI. Immediate post-partum initiation of intrauterine contraception and implants: A review of the safety and guidelines for use. Aust N Z J Obstet Gynaecol. 2013;53(4):331-7. https://doi.org/10.1111/ajo.12095.

PMid:23635040

3. Chhari A, Zutshi V, Sharma R, Batra S. Comparison of post placental IUD with interval IUD. Int J Reprod Contracept Obstet Gynecol. 2015;4(4):1090-3. https://doi. org/10.18203/2320-1770.ijrcog20150433

4. Teal SB. Postpartum contraception: Optimizing interpregnancy intervals. Contraception. 2014;89(6):487-8. https://doi. org/10.1016/j.contraception.2014.04.013

PMid:24815100

5. Wildemeersch D, Goldstuck ND, Hasskamp T. Current status of frameless anchored iud for immediate intracesarean insertion. Dev Period Med. 2016;20(1):7-15.

PMid:27416620

6. Nerlander LM, Callaghan WM, Smith RA, Barfield WD. Short interpregnancy interval associated with preterm birth in US adolescents. Matern Child Health J. 2015;19(4):850-8. https:// doi.org/10.1007/s10995-014-1583-z

PMid:25062997

7. ASEANstat, Maternal Mortality Rate; 2021. Available from: https://www.aseanstats.org/publication/asean-maternalmortality-rate-infographic [Last accessed on 2021 Dec 24].

8. Budiarti I, Nuryani DD, Hidayat R. The Determinant of Using Long Term Birth Contraceptive Method (LTBCM) on KB Acceptor. J Kesehat. 2017;8(2):220. https://doi.org/10.26630/ jk.v8i2.490

9. Misnaniarti M, Ayuningtyas D. Unmet need for family planning in Indonesia and the policy strategy of intervention in several countries. Int J Reprod Contracept Obstet Gynecol. 2016;5(6):1680-5. https://doi.org/10.18203/2320-1770. ijrcog20161652

10. Winarni E, Dawam M. Family planning information, education and communication with contraceptive use. Kesmas. 2016;11(2):94-102. https://doi.org/10.21109/kesmas.v11i2.801

11. Westoff CF. Unmet Need for Modern Contraceptive Methods. DHS Anal Stud. No. 28; 2012. Available from: http://www. dhsprogram.com/pubs/pdf/as28/as28.pdf. [Last accessed on 2021 Dec 25].

12. Katheit G, Agarwal J. Evaluation of post-placenta intrauterine device (PPIUCD) in terms of awareness, acceptance, and expulsion in a tertiary care centre. Int $\mathrm{J}$ Reprod Contracept Obstet Gynecol. 2013;2(4):539. https:// doi.org/10.5455/2320-1770.ijrcog20131210

13. Agarwal K, Dewan $R$, Mittal $P$, Aggarwal A. Visibility of strings after postplacental intracesarean insertion of CuT380A and Cu375 intrauterine contraceptive device: A randomized comparative study. J Obstet Gynaecol India. 2017;67(5):324-9. https://doi.org/10.1007/s13224-017-0965-8 PMid:28867882

14. Makins A, Taghinejadi N, Sethi M, Machiyama K, Thapa K, Perera G, et al. Factors influencing the likelihood of acceptance of postpartum intrauterine devices across four countries: India, Nepal, Sri Lanka, and Tanzania. Int J Gynaecol Obstet. 2018;143 Suppl 1:13-9. https://doi.org/10.1002/ijgo.12599 


\section{PMid:30225876}

15. ACOG. Immediate Postpartum Long-Acting Reversible Contraception. Vol. 128. United States: ACOG; 2016. p. e32-7.

16. Raghuwanshi R, Chavan S, Hegde LC. To assess the safety and expulsion rate of cut $380 \mathrm{a}$ in immediate postpartum period. Int J Clin Obstet Gynaecol. 2019;3(6):286-9. https://doi. org/10.33545/gynae.2019.v3.i6e.427

17. Singh S, Das V, Agarwal A, Dewan R, Mittal P, Bhamrah R, et al. A dedicated postpartum intrauterine device inserter: Pilot experience and proof of concept. Glob Health Sci Pract. 2016;4(1):132-40. https://doi.org/10.9745/GHSP-D-15-00355

18. Heller R, Johnstone A, Cameron ST. Routine provision of intrauterine contraception at elective cesarean section in a national public health service: A service evaluation. Acta Obstet Gynecol Scand. 2017;96(9):1144-51. https://doi.org/10.1111/ aogs. 13178

PMid:28590560

19. Cooper M, McGeechan K, Glasier A, Coutts S, McGuire F, Harden $\mathrm{J}$, et al. Provision of immediate postpartum intrauterine contraception after vaginal birth within a public maternity setting: Health services research evaluation. Acta Obstet Gynecol Scand. 2020;99(5):598-607. https://doi.org/10.1111/aogs.13787 PMid:31837002

20. Braaten KP, Benson CB, Maurer R, Goldberg AB. Malpositioned intrauterine contraceptive devices: Risk factors, outcomes, and future pregnancies. Obstet Gynecol. 2011;118(5):1014-20. https://doi.org/10.1097/AOG.0b013e3182316308 PMid:22015868

21. Singh U, Sonkar S, Yadav P, Dayal M, Gupta V, Saxena S. Comparative evaluation of postpartum IUCD versus interval IUCD at a tertiary care centre in Allahabad, India. Int J Reprod Contracept Obstet Gynecol. 2017;6(4):1534. https://doi. org/10.18203/2320-1770.ijrcog20171423

22. Makins A, Taghinejadi N, Sethi M, Machiyama K, Munganyizi $P$, Odongo $\mathrm{E}$, et al. FIGO postpartum intrauterine device initiative: Complication rates across six countries. Int J Gynaecol Obstet. 2018;143 Suppl 1:20-7. https://doi.org/10.1002/ijgo.12600 PMid:30225873

23. Muganyizi PS, Kimario G, Ponsian P, Howard K, Sethi M. Clinical outcomes of postpartum intrauterine devices inserted by midwives in Tanzania. Int J Gynaecol Obstet. 2018;143(1):3842. https://doi.org/10.1002/ijgo.12603 PMid:30225875

24. Makins A. Clinical outcomes of postpartum intrauterine devices inserted by midwives in Tanzania. Int $\mathrm{J}$ Gynaecol Obstet. 2018;143(1):38-42. https://doi.org/10.1002/ijgo.12603 PMid:30225875

25. Çelen Ş, Sucak A, Yıldız Y, Danışman N. Immediate postplacental insertion of an intrauterine contraceptive device during cesarean section. Contraception. 2011;84(3):240-3. https://doi.org/10.1016/j.contraception.2011.01.006 PMid:21843687

26. Lucksom PG, Kanungo BK, Sebastian N, Mehrotra R, Pradhan D, Upadhya R. Comparative study of interval versus postpartum
Cu-T insertion in a central referral hospital of North East India. Int J Reprod Contracept Obstet Gynecol. 2015;4(1):1. https:// doi.org/10.5455/2320-1770.ijrcog20150209

27. Goldthwaite LM, Sheeder J, Hyer J, Tocce K, Teal SB. Postplacental intrauterine device expulsion by 12 weeks: A prospective cohort study. Am J Obstet Gynecol. 2017;217(6):674 e1-8. https://doi.org/10.1016/j.ajog.2017.08.001 PMid:28826801

28. Jatlaoui TC, Whiteman MK, Jeng G, Tepper NK, Berry-Bibee E, Jamieson DJ, et al. Intrauterine device expulsion after postpartum placement: A systematic review and meta-analysis. Obstet Gynecol. 2018;132(4):895-905. https://doi.org/10.1097/ aog.0000000000002822 PMid:30204688

29. Hay P. Vaginal discharge. Medicine. 2018;46(6):319-24. https:// doi.org/10.1016/j.mpmed.2018.03.006

30. Ilankoon IM, Gunawardana CS, Fernandopulle RC, Perera PP. Vaginal discharge assessment form for utilization by primary health care workers in a community setting. J Gynecol Womens Health. 2018;9(3):555763. https://doi.org/10.19080/ jgwh.2018.09.555763

31. Singh S, Das V, Agarwal A, Dewan R, Mittal P, Bhamrah R, et al. A dedicated postpartum intrauterine device inserter: Pilot experience and proof of concept. Glob Health Sci Pract. 2016;4(1):132-40. https://doi.org/10.9745/GHSP-D-15-00355

32. Heller R, Johnstone A, Cameron ST. Routine provision of intrauterine contraception at elective cesarean section in a national public health service: A service evaluation. Acta Obstet Gynecol Scand. 2017;96(9):1144-51. https://doi.org/10.1111/ aogs. 13178 PMid:28590560

33. Cooper M, McGeechan K, Glasier A, Coutts S, McGuire F, Harden J, et al. Provision of immediate postpartum intrauterine contraception after vaginal birth within a public maternity setting: Health services research evaluation. Acta Obstet Gynecol Scand. 2020;99(5):598-607. https://doi.org/10.1111/aogs.13787 PMid:31837002

34. Braaten KP, Benson CB, Maurer R, Goldberg AB. Malpositioned intrauterine contraceptive devices: Risk factors, outcomes, and future pregnancies. Obstet Gynecol. 2011;118(5):1014-20. https://doi.org/10.1097/AOG.0b013e3182316308 PMid:22015868

35. Singh U, Sonkar S, Yadav P, Dayal M, Gupta V, Saxena S. Comparative evaluation of postpartum IUCD versus interval IUCD at a tertiary care centre in Allahabad, India. Int J Reprod Contracept Obstet Gynecol. 2017;6(4):1534. https://doi. org/10.18203/2320-1770.ijrcog20171423

36. Makins A, Taghinejadi N, Sethi M, Machiyama K, Munganyizi P, Odongo $\mathrm{E}$, et al. FIGO postpartum intrauterine device initiative: Complication rates across six countries. Int J Gynaecol Obstet. 2018;143(1):20-7. https://doi.org/10.1002/ijgo.12600 PMid:30225873

37. Muganyizi PS, Kimario G, Ponsian P, Howard K, Sethi M. Clinical outcomes of postpartum intrauterine devices inserted by midwives in Tanzania. Int J Gynaecol Obstet. 2018;143(1):38-42.

Author Query???

AQ1: Kindly cite reference $30-37$ in the text part 